\title{
19 NON-RESPONSE BIAS IN A COMMUNITY SURVEY OF DRINKING, ALCOHOL-RELATED EXPERIENCES AND PUBLIC OPINION ON ALCOHOL POLICY
}

doi:10.1136/injuryprev-2012-040580e.19

${ }^{1} \mathrm{~B}$ Maclennan*, 1,2 K Kypri, ${ }^{1} \mathrm{~J}$ Langley, ${ }^{3,4} \mathrm{R}$ Room. Injury Prevention Research Unit, University of Otago, New Zealand; ${ }^{2}$ School of Medicine and Public Health, University of Newcastle, Australia; ${ }^{3}$ Centre for Alcohol Policy Research, Turning Point Alcohol and Drug Centre, Australia; ${ }^{4}$ School of Population Health, University of Melbourne, Australia

Background The continuing decline in response rates to household surveys is a concern for the health and social sciences as it increases the risk of selective non-response biasing the estimates of interest. Aim To assess non-response bias in a postal survey measuring drinking behaviour, experience of harm and opinion on local government alcohol policies among residents in six New Zealand communities.

Methods The Continuum of Resistance model, which suggests that late respondents to a survey are most similar to non-respondents on the measures of interest, was used to guide our investigation.

Results Men, younger people, those of Māori descent and those living in more deprived areas were less likely to respond to our survey than women, older people, those not of Māori descent and those living in comparatively affluent areas. Late respondents more closely resembled non-respondents demographically than early respondents. The prevalence of binge drinking and experience of assault was higher, and support for restrictive local government alcohol policies lower, among late respondents. Assuming the drinking behaviour and alcohol-related experiences of non-respondents were the same as those of late respondents, prevalence was under-estimated by $3.4 \%$ (relative difference: $13 \%$ ) and $2.1 \%$ (relative difference: $21 \%$ ) for monthly binge drinking and assault respectively. There was little evidence of bias in estimates of policy support.

Contribution to the Field The findings add to a growing body of evidence suggesting that surveys under-estimate risk behaviour because of selective non-response. Notably, public opinion may not be subject to such misestimation. 